\title{
Social Differentiation and Integration for Rural Villagers in Ethnic Group Areas A Case on Village A
}

\author{
He Xiaobo \\ Yunnan University of Finance and Economics, Kunming, P.R. China 650221 \\ ( hexiaobo921@ hotmail.com )
}

\begin{abstract}
At present, China's social structure has being changed, which had people's productive model, living style, social relations and cultural values changed extremely. In the transformation from traditional farming society to modern industry society, the differentiation of rural villagers is the most significant and remarkable. And their differentiations mainly focus on vocations, profits, areas, social ranks and social organizations. The following passage sets Village A as an example to analyze the internal and external factors to cause social differentiation. Meanwhile, Village A is a typical micro-perspective of empirical study for us to know about China's real society. The paper attempts to analyze the differentiations of rural villagers in ethnic areas, to find out the reason and supply some solutions to improve social integration from the perspective of institution, function and culture.
\end{abstract}

Keywords: social differentiation, social integration, rural villagers, social structure.

\section{Introduction}

China has being stepped into the period of social transformation, so the social structure has been changed a lot than before. China's traditional society is an agricultural society with high homogeneities and low differentiations. In modern society, especially after the time of reform and opening-up, the social productive power has been developed extremely, and the differentiation for rural villagers appeared as significant traits, outstanding influences and diverse directions, so the differentiation for rural villagers among social stratums is the most important and significant, and would go on with the development of social modernization.

The research on the villagers' social differentiation is helpful to know about China's stratum and reality. The existed research for the topic focuses on three directions------the first is macro-perspective: from the differentiation of politics, economy and culture to analyze social integration; the second is mesoperspective: from social structure and ladder to analyze integration; the third is micro-perspective: from profits, marriage, ideas to analyze integration.
China is a long history country with 56 ethnic groups which have diverse cultures and traits. The research on Village A is a mirror to know ethnic areas better.

\section{Social Differentiation for Rural Villagers in} Ethnic Areas -- A Case on Village A

\subsection{Vocation Differentiation: from Job to Status}

Peasant is a concept to describe a job. It means people's mode of production and income are mainly or only original from farming. It is a social group coordinated with worker, cadre and intellectual. After 1958, people were divided into city-dwellers and peasants, so the social mobility was restricted in land, and peasant standed for the transformation from a job to a status. Village $\mathrm{A}$ is an ethnic rural village located in the west of China. All villagers are Bai People and their main production mode is farming for thousand years. Recently, with the development of urbanization, yields of arable land are less than $200 \mathrm{~m}^{2}$, so villagers can not survive within the land. More and more villagers go into cities to find a job, 
or turn into silver handicraftsman in village. 1 In 2013, 90\% villagers are engaged in non-agriculture, and $70 \%$ incomes are from silver manufacture.

2.2 Profit Differentiation: Enhance the Gap between the Wealth and Poor

Due to the difference of geographical location, policy, economic base and peasant's quality, the gap between the wealth and poor has been enhanced. Village a is an AAAAA tourist spot.2 The income gap between agricultural peasants and nonagricultural villagers is so serious. According to the dada from local statistics bureau, the average income for agricultural peasants is about RMB 600,but for the other is more than RMB 36,000. The former is just $1 / 12$ of the latter.

\subsection{Areas Differentiation: Two-stage Development}

\section{between Urban and Rural}

China's reform has being taken in the out-off-balance of regions and policies, including prior development for coasts, less people rich firstly and Western Development Policy and so on. The development has been enforced from East to West and step by step. The East areas can take the advantage of the unfair policies so much. Although the government has realized the inequality, the distinction between the two sides was still critical. Village A was in the name of Western rural areas, but villagers' mode of production, life and values was so different than before. Comparing with urban, its development was still in the low level in deed.

${ }^{1}$ silver handicraftsman: Village A is famous for silver handcraft. In the past years, villagers engaged the task after farming.

${ }^{2}$ AAAAA tourist spot: the highest level of tourist spot, approved by China's authority.

\subsection{Rank Differentiation: Create Edge Social Groups}

Urbanization adjusted the vocation structure in rural areas and made social mobility and rank speed up. In traditional society, villagers laid much emphasis on land and family. People connected with each other in a net named acquaintance society. But now, social transformation has made more villagers to be edge social group. They lost their vocation (farming), villagers fellows, culture and so on. Village A has a population of $10247.99 \%$ people are Bai People with Bai Language. $90 \%$ villagers are either peasants or workers. They work and live in city with urban life style. Their kids grow up in the city. But they have not been accepted by city culture. They turned into edge social groups for they had no own cultures , organizations and belongs.

\subsection{Organization Differentiation: from Single to} Diverse

From the planning economy to market economy, social organization in China was developed from one mode to diversity. Besides the eco-government, more social groups and organizations appeared to stand for different profit. Village $\mathrm{A}$ is one of the basic authority units in China, its power mainly concerns on village government. Due to the development of market economy, government's power has been decreased, but the power of social organizations and elites has been strengthened. By the end of 2013, the self-ruled organizations in Village A was amount to 7, including supervising, cooperation and market risks. Meanwhile, more elites appeared in the community and played important role in general village affairs. Take Cun Fabiao as an example, who was well-known for his silver handcrafts. He was rich, high prestige and powerful in the local place. Because of personal authority and charm, such elites 
would do much effects to villagers life more and more.

3. Traits and Tendency of Social Differentiation for Rural Villagers

\subsection{The Gap between the Wealth and Poor Would Be Enhanced}

The current differentiation taken place for the production power was relatively undeveloped, and labors connected on physical intensive areas. The mechanism for the differentiation was not welldeveloped. But with the development of market economy and social structure transformation, social differentiation would be decided by capital, knowledge, techniques, resources and so on. The income gap among villagers would be strengthen. Meanwhile, the income gap would make power, social status, reputation, resource in another unequal recycle leading the Matthew Effect.

\subsection{The New Edge-group Would Step toward Core} System.

The differentiation made some new edge-group appear, such as migrant worker from peasants, folk artists from peasants, businessman from peasants and so on.3 They have done the job differently from traditional peasants. They were neither workers, artists, businessman nor peasants. But due to the market need, all the edge-group standed for the future tendency and directions. The edge people's profit allocation, resources, reputation, culture, values would be accepted by society from the edge to the core.

\subsection{The Development between Urban and Rural}

\section{Would Be Considered Both}

The inequality between urban and rural, the West and the East, the inland and the coast, has influenced on

\footnotetext{
${ }^{3}$ Migrant worker, artists and businessman from peasants: the people engage in non-agricultural job, but they have the status of peasant.
}

the balanced development of China. To make socialism common prosperity come true, we must clear up two unequal development policy in urban and rural. Social mobility would be strengthen in various careers, areas, cultures, status and individuals. A modern and civilized society ought to have equal, proper and prospected social structure.

\section{The Internal and External Factors to Cause Social Differentiation}

\subsection{Internal Factors}

\subsubsection{The Change of Elementary Economic Structure}

Economic basis decides the development of social relations, structures, and cultures. The change of social structure leads to social differentiation. The traditional society has low social mobility, high social distinction and high social homogenous. The economic structure bases on farming civilization. It is a natural economic form. The current society has to obey the rules of market economy for it influences on all the aspects of daily life. The transformation from natural economy to market economy must lead to the differentiation in the course of production, distribution, exchange and consume. Despite in the same economic mode society, individuals, environments, resources and policies are so different to form various differentiations. People in Village A have changed the natural economic form into a production mode. Their life mainly relies on nonagricultural economy, which is so different than before, leads to form new life style, values and cultures.

4.1.2 Double Development Policy between Urban and Rural

Although the disadvantage of double development policy between urban and rural has drawn so much attention, there would be a long way to eliminate the 
disadvantages in that it had a strong base. The unfair development policy made people in different future, even some serious problems and conflicts would appear. The new edge-groups served as a bridge to cover the urban and rural, meanwhile the diversity of the edge-groups also made social structure unstable and complicated.

\subsection{External Factors}

\subsubsection{Impacts of Policy}

Policy is an ordinary regulation and rule to guide social mobility, adjust distribution, improve social relations and solve social problems. However, government formulates some policies in order to solve many problems for certain area and people, so policy is special sometimes. Village A is a Bai village in western of China. Central and local governments draw up preferential policy to improve the areas development. But because of the different understanding, enforcement of the policy and different individuals, people can benefit so different from the same policy. Only for some people, can they take advantage in the policy and make higher social differentiation and mobility.

\subsubsection{Elites Effect}

Although the opening and mobility in society are enhanced, the main power to flow for social members are still elites. According to Pareto's Elites Theory, elites are just a small part in society. They are outstanding in intelligence, characteristics, ability and resources, so they can do more effect than ordinary people do. Elites are consisted of politics, economics, cultural and social elites. They have strong and powerful influence in all walks of life. Most people respect and admire the elites so much to set them as good models. Elite's mobility make the social members differentiation and flow speed up.

\section{Social Integration for Rural Villagers in Ethnic} Areas

\subsection{Institution Integration}

5.1.1 Set Equal and Proper Institution for Social Mobility and Social Structure

A free and open institution serves as a safety valve to release energy, decrease social crisis and solve social problem. Generally speaking, when the social mobility is more influent, organic society can have all levels activated in social structure better, and the future of the whole society is much brighter. The differentiation for rural villagers in ethnic areas is original from the reform of elementary economic mode. The differentiation is neither good nor bad. It is a critical concept existed in social facts. A good institution can make society go well. For this reason, we must establish more good institutions to defend the society, especially for disadvantaged group. For the serious gap between the wealth and poor resulted from power abuse or crime, institutions must be enforced to fight against.

5.1.2.Improve the Institution Integration from 3 Roles Government has 3 roles as making policy, institution enforcement and supervisor. All three roles are included into the institution integration for government. Government is responsible to make proper and equal institution to guide social differentiation. What's more, the enforcement is important too. A proper evaluation system should be used to guide and supervise the outcome of institution. China is well known as "Strong Government, Weak Society". Only on this way, can the 3 roles be integrated well for the organic whole. 


\subsection{Function Integration}

5.2.1.Make Urbanization to Enlarge Rural Villagers'

Life and Development Space

China has a long history of the household registration system, unequal development policy between urban and countryside. We pay more attention on heavy industry rather than light industry and service. So the level of urbanization relatively falls behind than other developed countries do. More experience to show that urbanization is a useful way to develop scale economy, especially for industry and service. For this reason, we must improve urbanization to enlarge rural villagers' life and development space rather than countryside.

5.2.2 Cultivate More Powerful Social Organizations and Elites to Enhance Social Function Integration

The differentiation of social organizations have being changed from one model to diversity------ in the past, government had absolute power, but now, market need is the first, also more and more self-rule powers participated society management and construction. In the course, many powerful social organizations and elites turn out, which is a useful and important supplement for government to realize social function integration.

\subsection{Cultural Integration}

5.3.1 Development Education to Improve Cultural Integration

Peasants have low quality of knowledge and techniques, which is the main factor to restrict their social mobility toward higher social ladder. The key for this phenomenon is the role of education. Science, techniques and knowledge will play more and more important role in the future. But there is an unequal and unfair education resources distribution in urban and rural, the east and the west, such as teachers' quantity and quality, books, money, enrollment and so on. So people from the lower social ladder have less chance to receive education and training. This fact restricts people to flow toward higher social ladder and make the social structure in a bad situation all the time. The government should invest more high quality teachers, money, information, chance, equal enrollment, institution to improve the undeveloped areas. Education is the most important model cultural integration.

5.3.2 Take Advantage of Minority Culture for Cultural Integration

Ethnic group has its own sub-culture which is formed in certain districts, economic activity and life style. Minority culture has its outstanding traits, which serves as a net to unite people and have group identity. Village A has its own Bai culture, such as Benzhu belief, ${ }^{4}$ Bai clothes, Bai language, food and so on. All the ceremonies or living styles are parts of minority culture. They play so important part in uniting social groups and reestablishing social relations.

All in all, transformation of social structure has people's production model, living style, social relations changed extremely. The changes are the differentiations for all walks of life, such as vocations, profits, areas, social stratum, social organizations and so on. Some differentiations are helpful for the better social mobility, but some do bad effect in stability of social structure. It is necessary to make use of the differentiations to improve social integration from institution, function and culture.

\footnotetext{
${ }^{4}$ Benzhu Belief: Regard the local god as Bai people's faith.
} 


\section{References}

(1) Anthony Giddens. 2003. New Rules and Regulations for Methodology of Sociology ------ A Critical Viewpoint to Explain Sociology. Beijing: Social Science Academic Pres

(2) Fei Xiaotong. (1985). Native China. Beijing: Sanlian Bookstore

(3) Michael J.Piore. (1993). The Second Industrial Divide. Oxford University Press,

(4) Ma Rong. (2004). Ethnosociology: Research on Ethnic Group Relations in Sociology.] Beijing: Beijing University Press

(5) Paul Bairoch. (1981). Disparities in Economic Development Since the Industrial Revolution. New York

(6) Wang Yueping. (2011). Ritual Reconstruction and Social Intergation: A Case on Village Y in Border of China and Vietnam. Journal of Guanxi University for Nationalities, 9

(7) Yuan Fang. (1998). Transformation of Chinese Social Structure. Beijing: Social Science Academic Press

(8) Yu Lian. (2013). Villagers' Differentiation and Transformation of Marriage Cycle------Based on Village Dagu Investigation. Journal of Wuhan University, 1 